\title{
AN EFFECTIVE PROCUREMENT AND INVENTORY MANAGEMENT SYSTEM FOR ABC TEXTILE SHOP
}

\author{
S.F Shazna \\ Department of Information and Communication Technology \\ Faculty of Technology \\ Rajarata University of Sri Lanka
}

\begin{abstract}
ABC}$ is a retail textile shop is situated in a suburb area of Anuradhapura, Sri Lanka. They have a routine of daily sales and weekly purchases and have a monthly expense of utility and salary payment for workers who work on sales. For the moment they are running a filebased system like Excel sheet for inventory keeping, purchasing, maintaining vendors' details and workers details, daily sales and profit margins including number of items on each variety with a custom variety code. Since there is poor network coverage in the area, they are unable to use an open source online inventory system. So, it was decided to implement an inventory management system for them. By developing, "Procurement and Inventory Management System", they can reduce their time for entering, updating, calculating and retrieving data. Not only that but also, they can avoid data redundancy, data consistency, high data security, privacy, and easy recovery. They can enter memos or special notes and they can filter and search related data. And, they can export grid view data to Microsoft excel sheet. The system built has been able to have a positive and beneficial impact on both organization and consumers. To develop the system, it was used agile software development methodology, the SQL Server 2014 was used as the database, Visual Studio 2010 as developer tools and $\mathrm{C \#}$ is used as the programming language. The results of this study to get a system that has been developed that can make transactions which generate transaction reports, and which update database and remind notes for consumers thus greatly supporting the activities at the $\mathrm{ABC}$ shop.
\end{abstract}

Keywords- Inventory, Inventory control, system, Administrator, general user, GRN, purchase order

\section{INTRODUCTION}

\section{A. Background of the existing system}

Procurement and inventory management are two main processes for any organization specially in the retail sector.
These two processors should be updated and managed properly in order to have a smooth functioning of the business. For an example, an issuance of good receive note (GRN) would increase the inventory while a point of sale (POS) could decrease the inventory. There will be difficulties and troubles for both the organization and the customers, in case of an improper inventory management system. Even though there is a need for proper inventory management system, most of the time organizations (Example: retail and SME businesses) use traditional manual bookkeeping and file based spread sheet like MS excel.

$\mathrm{ABC}$ is a textile shop with all kinds of clothes. They have established it in January 2017.The problem with ABC textile shop is not yet have a computerized relational database management system that can solve transactional problems such as difficulties in maintaining stock details, sales details, purchase details, payments, notes maintaining and so on. Since there is poor network coverage in the area, they are unable to use an open source online inventory system. So it was decided to implement an inventory management system for them. System runs manually to keep vendor details until the receipts of payments are done for vendors. Because of this manual process organization owner and the file based system user face some difficulties such as less accuracy, nonreliability, entering duplicated data, displaying duplicated data, re-check again and again, change or delete data easily without permission, inefficient and ineffective, confusing to view separate data and Time consuming and so on. This research proposes to develop "Procurement and Inventory Management System" software, which will help to overcome the drawbacks of the existing manual system.

\section{B. Proposed system}

Inventory management system is important to ensure the quality and productivity of the organization. Advances in technology and well-designed software make inventory systems so easy to handle. [1]The developed system should be able to manage vendor details, purchased orders, Good Received Note, stock availability and inventory management with item codes, generate point of sales and messages. They can enter any memos or essential notes and, they can filter 
and search related data. Not only that but also the system will be reliable, and they can update their data efficiently that means, it will take less time to save or update the many transactions. And, they can export grid view data to Microsoft excel sheet. This system limits access using user login. Only authorized users can access the system. Therefore, only they can change or add data. So, data will be secured. The main objective of this Procurement and Inventory Management System is to eliminate the identified drawbacks of the existing system by introducing a better solution, which has an ability to reduce all those drawbacks.

To develop this solution, it requires 64-bit (x64) processor (Core i5), 4 Gigabyte (GB) RAM, 500 GB available hard disk space and other basic essential hardware resources. In addition, it requires software such as SQL Server 2014 Management Studio software, Visual studio 2010 and MS Excel 2010 mainly. As a programming language C\# is used to develop the solution. This study uses agile methodology as a software development life cycle methodology, which is an iterative process. Whenever the requirement changes, it goes the process repeatedly until user gets satisfied.

The system goes under five phases. Those are system analysis, design, development, testing and maintenance. The act, process, or profession of studying an activity typically by mathematical means in order to define its goals or purposes and to discover operations and procedures for accomplishing them efficiently.

It is more of a thinking process and involves the creative skills of the System Analyst. It attempts to give birth to a new efficient system that satisfies the current needs of the user and has scope for future growth within the organizational constraints. The research used observation and interview of employer and current system user to gather the requirement. And analyzed the documents and MS excel sheet too. The result of this process is a logical system design. System analysis is an iterative process that continues until a preferred and acceptable solution emerges. This phase is essential to identify their requirements. [2]

- Check whether username and password are authorized before login to system.

- Register new vendor details.

- View \& edit existing vendor details.

- Search vendor details by entering keywords.

- Retrieve all or specific details related to vendor.

- Add any comments or notes, exporting all or specific details to Microsoft Excel sheet.

- Register new item details, should be able to edit existing item details.

- Search item details by entering keywords.

- Retrieve all or specific details related to item.

- Generate Purchase Order.

- Create GRN.
- Add point of sales and functional requirements.

Systems design is the process of defining the architecture, components, modules, interfaces, and data for a system to satisfy specified requirements. Systems design be the application of systems theory to product development.

The design phase is concerned with the physical construction of the system. This study mainly considered the computer system architecture (hardware, operating system and programming, design of user interfaces (forms, reports, etc.), design of system interfaces (for communication with other systems), and security issues. It is important that the proposed design be tested for performance, and to ensure that it meets the requirements outlined during the analysis phase [2]. Inventory Module, Vendor Module, POS (Point of Sale) Module, Purchase Order Module, Good Received Note Module and Payment Module are recognized as main modules in this study.

System requirements analysis in this system designed using use case diagrams, Entity Relationship (ER) diagram, class diagram, activity diagram and sequence diagram [2]

\section{RESULTS AND DISCUSSION}

The "Botter and Fortuin et al. (2000)" showed that there are several aspects concur in making demand and inventory management for the spare parts to managed. To manage the stocks from its initial stage is the critical task and most of the time it's affects the entire chain [3]. In software engineering, a software development methodology (also known as a software development life cycle) is a division of software development work into distinct phases (or stages) containing activities with the intent of better planning and management. It is often considered a subset of the systems development life cycle. The methodology may include the pre-definition of specific deliverables and artifacts that are created and completed by a project developer to develop or maintain an application. Common methodologies include waterfall, prototyping, iterative and incremental development, spiral development, rapid application development, extreme programming and various types of agile methodology. And this study has used agile methodology as a software development life cycle. Agile methodology has grown to be among the most popularly used software development methodologies in today's world. 


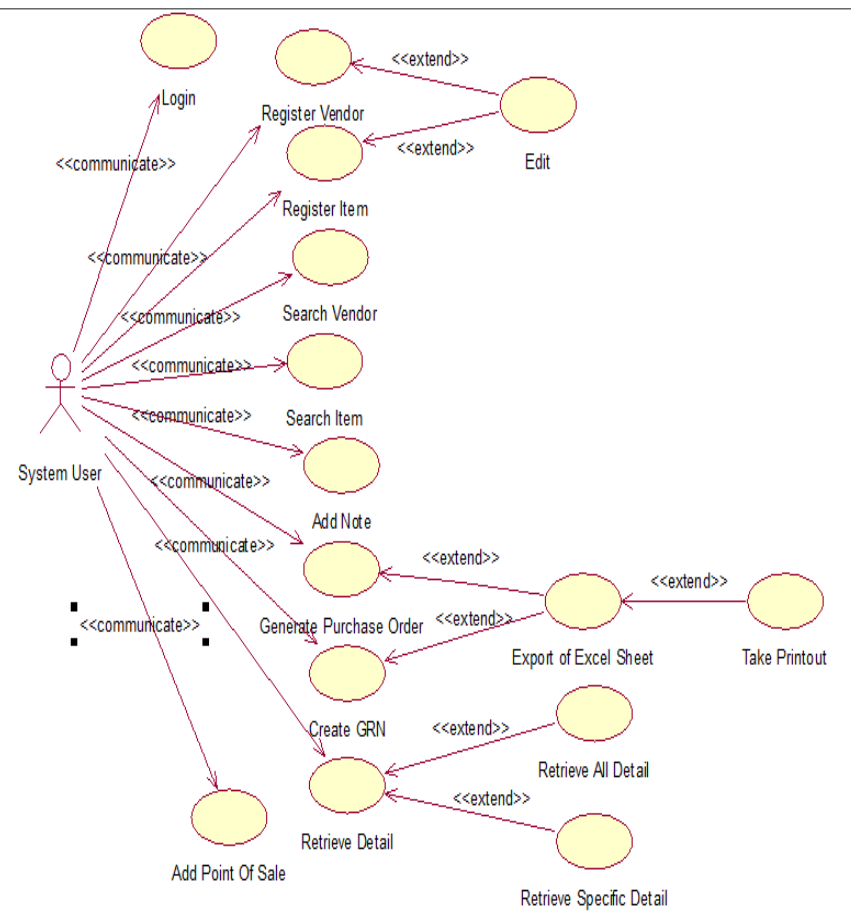

Figure 1. Use case diagram

This study has used this agile methodology since customers requirement gets vary. In this methodology user involvement is high. Therefore, the product output will be most suitable according to the requirement. In addition, this methodology is more flexible (on the other hand, it responds to the change), has a better communication, product outcome is faster than other methodologies such as waterfall or prototype methodologies.

\section{A. Database Development}

The system interface was coded in Microsoft.Net (pronounced dot net) integrated environment with Visual Basic language during the system development phase. The database design has done in Microsoft SQL Server Express 2014. Microsoft SQL server is a popular choice of database to use in stand-alone applications. Microsoft SQL is the most widely used open source relational database management system in the world.

Microsoft Visual Studio is an integrated development environment (IDE) from Microsoft.Visual Studio uses Microsoft software development platforms such as Windows API, Windows Forms, Windows Presentation Foundation, Windows Store and Microsoft Silverlight. It can produce both native code and managed code.

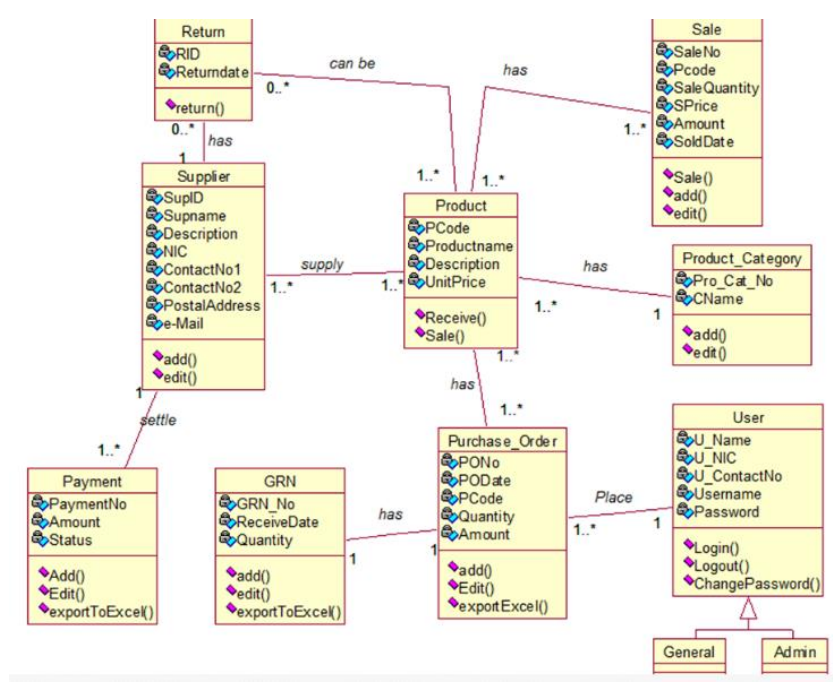

Figure 2. Class diagram

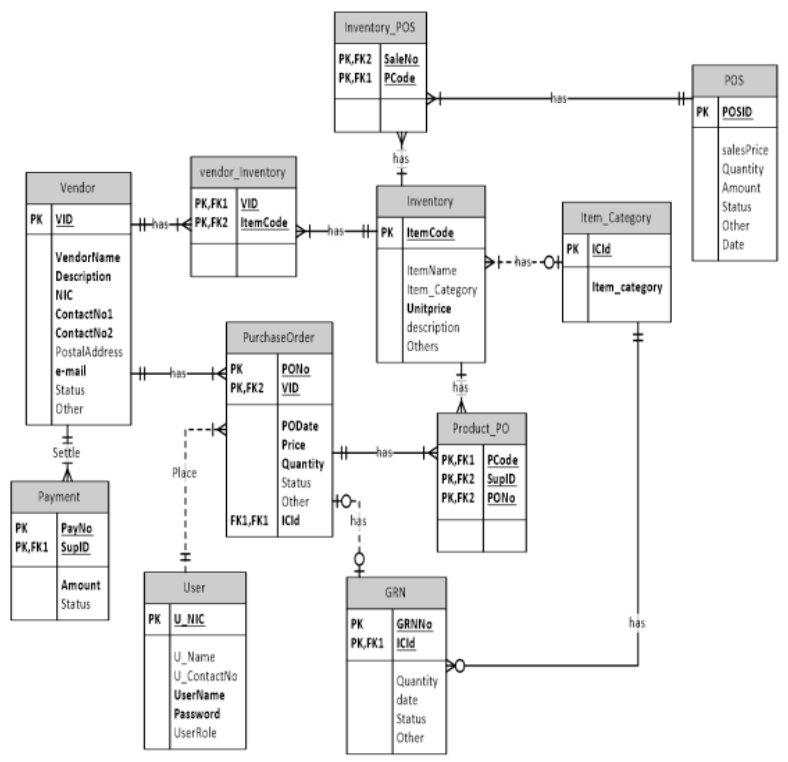

Figure 3. ER diagram 


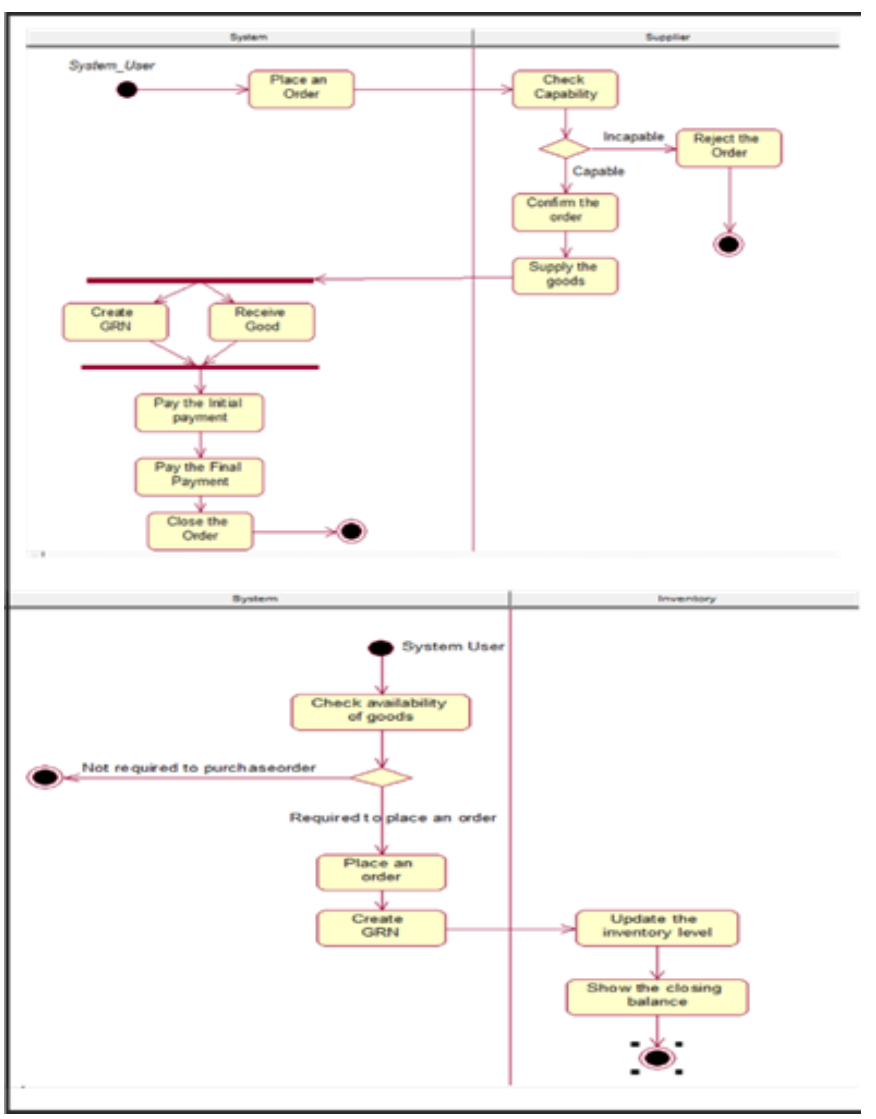

Figure 4. Activity diagram for vendor and inventory module

\section{B. Interface development}

Visual Studio includes a code editor supporting IntelliSense (the code completion component) as well as code refactoring. The integrated debugger works both as a sourcelevel debugger and a machine-level debugger. Other built-in tools include a forms designer for building GUI applications, web designer, class designer, and database schema designer. It accepts plug-ins that enhance the functionality almost at every level, including adding support for source-control systems (like Subversion) and adding new toolsets like editors and visual designers for domain-specific languages or toolsets for other aspects of the software development lifecycle (like the Team Foundation Server client: Team Explorer). Visual Studio supports different programming languages and allows the code editor and debugger to support (to varying degrees) nearly any programming language, provided a language-specific service exists. However, this research has used $\mathrm{C \#}$ as a programming language. Results of the study can be seen by the interface as follows.

\section{User Login interface}

There are two user types. Those are administrator and general users. The users who has administrative access, when they enter correct username and password, then they can access to administrator screen. The general users can login to main screen when they enter the username and password correctly. Both users have same login interface but separate access screens. If users forget their password, they can reset the password. Then their password will be reset to their NIC (National Identity Card) Number. And after login they can change the password as their requirement.

The users who has administrative authority. They have the authority to create more administrators and general users who have only access to main screen. However, they cannot access to administrative screens. And, administrators can create item category. It includes Item category code and the name such as "CLTS" for Color Less T-Shirt and "LSS" for Long Sleeve Shirt. All the interfaces have validations to limit mistakes done by the users. For example, if user entered same item category code, the description, system provides an error message that code, or description is already exist.

\section{Main Interface and the administrator interface}

The administrators and the general users both have access to main interface. Most of the time general users' role is to update the system through the main interface and administrator's role is to monitor the system via main interface. In the main screen each image represent button to navigate to next screen. This system shows the process flow to understand easy the users regarding the system.

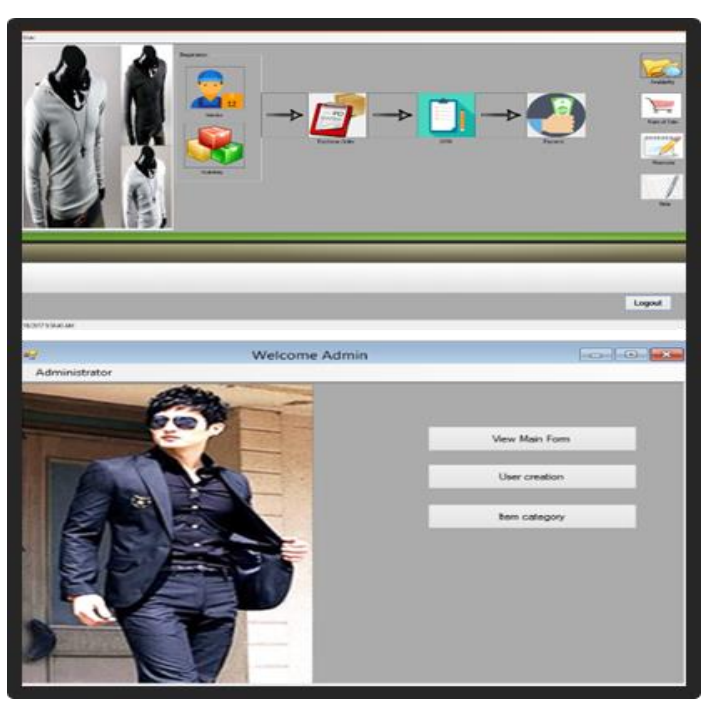

Figure 5. Main screen and Admin Screen

\section{Vendor Form}

This interface helps to maintain vendor's details. It is useful to make payments and keep track purchase orders and good received notes as well. The system validates whether the mandatory fields are updated, NIC number and contact numbers updated correctly, avoid duplicates so on. The system allows the vendor's details export to excel sheet. 


\section{International Journal of Engineering Applied Sciences and Technology, 2021 \\ Vol. 5, Issue 9, ISSN No. 2455-2143, Pages 76-82 \\ Published Online January 2021 in IJEAST (http://www.ijeast.com)}

There are several tabs used to insert, edit, search and deactivate data. When searching this system has a unique way. This study has used a dropdown method to select whether the search keyword should exactly match, or it contains in the results.

\section{Inventory registration interface $\&$ availability interface}

Inventory form registers all the inventory items which has bought to sales purpose. The system generates a unique item code for each item under item category. And the form will update the name, the description, and the unit price of the item. Whenever the item received according to the GRN, stock is increased and whenever the point of sales done, stock is decreased. So stock is updated in the real time. That can be check from the availability interface. This interface helps to search by several options specially by code and by name of the item $[2,4,5,6]$

\section{Notes and Reminder}

Note interface is useful to store essential notes. And reminder interface helps the client to remind the note in required date and required time. At that time system will pop up the note.

\section{PO, GRN and POS Interfaces}

The client generates purchase order (PO)which includes the product items to purchase. When generating the PO, system automatically generates a PO number which is uniquely identifies. Client has the facility to update the status whether the PO is sent to the client or pending or cancelled. So, when receiving the goods from the vendor, client creates the GRN across the PO number which is in sent status of the PO. Inventory gets update after GRN created. In the POS screen quantity field only allows up to available quantity. Otherwise it gives an error message "quantity must be less or equal to available quantity". Therefore, system has mainly focused to develop in user friendly manner. After transaction succeed inventory is updated.

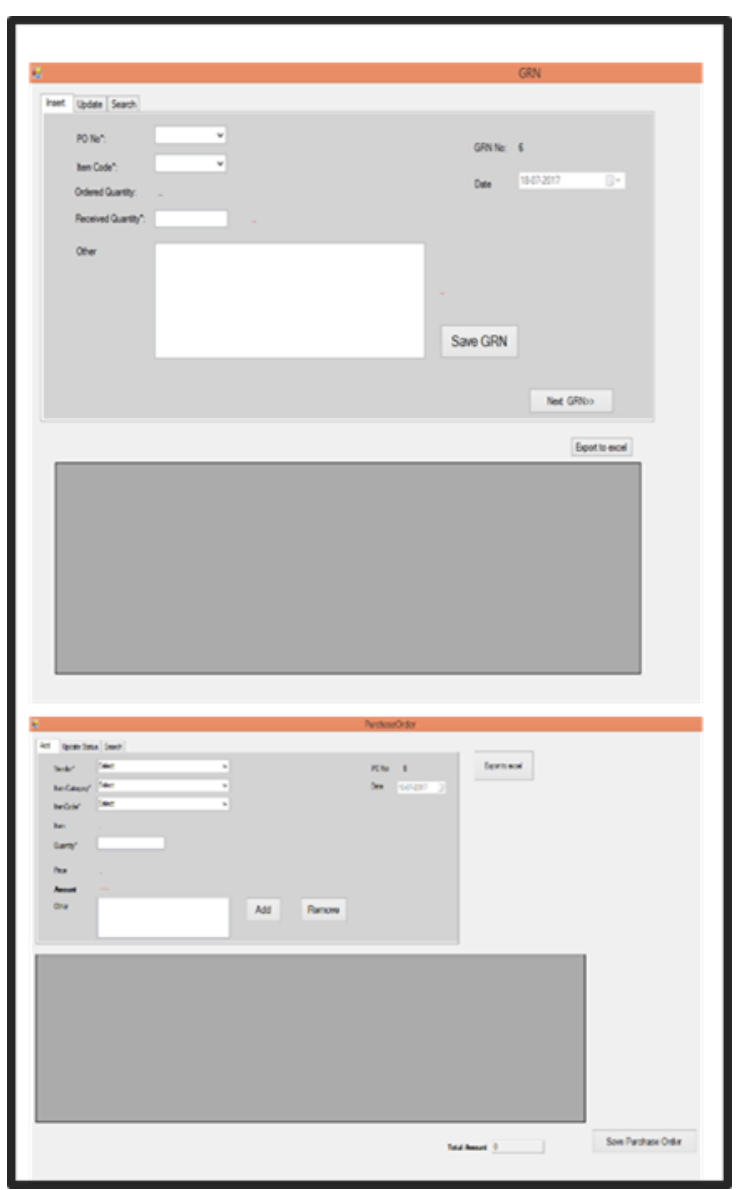

Figure 6. GRN and Purchase Order

\section{Payment interface}

This is the interface to update payment details of the vendor. So, this screen will list the unsettled purchase orders in ascending order. And, client can search by vendor or PO number. When the unsettled purchase order is selected, interface will display the total amount, outstanding amount. System can store data though payment is done in several installments.

\section{TESTING AND EVALUATION}

Software testing is carried out to make certain that software is performing as expected to perform under all expected conditions and for expected inputs. Software testing is iterative process, when one bug is fixed, it can cause other bugs to disappear, or other or new bugs may appear.[7]The test plan is a document describing the scope, approach, resources and schedule of intended test activities. It identifies amongst others test items, the features to be tested, the testing tasks, who will do each task, degree of tester independence, the test environment, the test design techniques and entry and exit criteria to be used, and the rational for their choice, and 
any risks requiring contingency planning. It is a record of the test planning process $[2,4,5,6]$.

\begin{tabular}{|c|c|c|c|c|}
\hline FUNCTION & TESTCASE & TEST DATA & EXPECTED RESULT & STATUS \\
\hline \multirow{9}{*}{$\begin{array}{l}\text { Register } \\
\text { Vendor }\end{array}$} & Mandatory fields = = empty & & Error message & Pass \\
\hline & Mandatory feilds < > empty & $\begin{array}{l}\text { Vendor name }=\text { abc } \\
\text { Nic-939692456 } \\
\text { Contact No }=05122222222 \\
\text { Postal address }=\text { Colombo1 }\end{array}$ & Insert Data & Pass \\
\hline & NIC $<>9$ & 9865 & Entor message & Pass \\
\hline & NIC $==9$ & 986523222 & No Error message & Pass \\
\hline & NIC allow typing Letters & & Not allowing & pass \\
\hline & NIC allow only numbers & 966523222 & allowing & pass \\
\hline & Contact no $<>10$ & 4582 & Error message & Pass \\
\hline & Contact no $=10$ & $0 \$ 12222222$ & No Error message & Pass \\
\hline & $\begin{array}{l}\text { Contact no allow conty } \\
\text { numbers }\end{array}$ & $\begin{array}{l}45266566565 \\
\text { bad }\end{array}$ & $\begin{array}{l}\text { Allowing } \\
\text { Not allowing }\end{array}$ & pass \\
\hline
\end{tabular}

Table 1.Sample test plan

Testing is a dynamic technique because it works with an executable section of the system. This study has used following test methodologies.

\section{Unit Testing}

Unit testing was used to test the small unit of the software component or module. Each units of the system have tested to identify the errors

\section{Integration Testing}

Integrated testing was used to test the integrated different tested individual program components. Integrated tests were developed from the system specification and integration testing was begun as soon as usable versions of some of the system components were available.

\section{System Testing}

All the three modules were integrated and tested in this testing stage. By recording the data in the interface, we can test its accuracy. The purpose of the testing is measuring the satisfaction with user requirements.

\section{Acceptance Testing}

This will be done by the client. Client will do the testing whether to accept the system or not.

\section{Performance Evaluation}

At each level the research has done some testing and correct the errors. And some more testing is in progress. This study is to provide reliable and usable system to the client.

\section{CONCLUSION}

ABC is a textile shop which sells all kinds cloths. They have established it in January 2017. They have a routine of daily sales and weekly purchases For the moment they are working manually using a file-based system like excel sheet for inventory keeping, purchasing, maintaining vendors' details and workers details, daily sales and profit margins including number of items on each variety with a custom variety code. Since there is poor network coverage in the area, they are facing difficulty to use an open source online inventory system. So this paper shows to develop an effective as well as efficient software system which solves the problem faced by all the textile shops in suburb areas. By development of "Procurement and Inventory Management System", they can overcome with from the drawbacks and achieve functional and non-functional requirement. To develop the system, it was used agile software development methodology which uses an iterative process to achieve the target. C\# (C Sharp) programming language is used to code. The ultimate outcome is to develop the system with minimum bugs and highly satisfy the client. The study has collected their requirements through interviews and Observation. The system is developed using Microsoft SQL Server 2014 and Microsoft Visual Studio 2010.

In system analysis phase this study identified Functional Requirements and non-functional requirements. As a result, it develops the user-friendly interfaces.

The research faces some limitations such as less testing due to lack of time period and changing requirement. Future research system can be enhanced by adding more features, which would increase the attraction with minimum errors. In future the research can develop the system for all the requirements and modules which are needed by client of ABC shop.

\section{REFERENCES}

1. Shaikh Sajid A.K; Niyati Raut .(2020). Study on VED Analysis, Stock-Review \& EOQ Techniques of Inventory Management vol. 4 Issue 11,ISSN No.2455-2143,(pages 218-223)

2. Kabir A, Han B. An Improved Usability Evaluation Model for Point-of-Sale Systems. 2016.

3. Rouwenhorst B, Reuter B, Stockham V, van Houtham GJ, Mantle RJ, Jism WH (2000). Warehouse Design and Control: Framework and Literature Review. European Journal of Operational Research. (122-3)

4. Fernando E, Condrobimo AR, Andwiyan D. RancangBangun (2018). Software Point of Sale (POS) Pada Kafe XYZ Dikota Jambi.JUTIS Vol.6 No.1; ISSN:2252-5351(pages 54-60). 
5. LI S, KUO X. The inventory management system for automobile spare parts in a central warehouse. Expert Systems with Applications. 2008;34(2):1144-1153.

6. Shen H, Tian T, Zhu H. A Two-Echelon Inventory System with a Minimum Order Quantity Requirement. Sustainability. 2019;11(18):5059.

7. Dimple Rajain; Dr. V K Pandey. (2016). Software Testing vol.1 Issue 8,ISSN No.2455-2143, (pages 161-164)

8. Definition of SYSTEMS ANALYSIS [Internet]. Merriam-webster.com. Available from: https://www.merriamwebster.com/dictionary/systems\%20analysis

9. Systems design [Internet]. En.wikipedia.org. Available from: https://en.wikipedia.org/wiki/Systems_design

10. Moon, Ilkyeong (2001), "Inventory Management and Production Planning and Scheduling", Interfaces ( 31.6), Pg.-125-127.

11.Koumanakos, Dimitrios P. (2008), "Hitachi Automotive Improves Efficiency and Inventory Control with Geac's System21", Business Wire.

12. N. Wartha, v. Londhe (2015), Context-Aware Approach to Enhancing and Privacy of RFID, Int. J. In computer. Science. 4 (pp.10,078-88).

13. Babar ,MA .; Paik Hye young. (2009). Using scrum in Global software Development. 